El gran libro del petricor

verne.elpais.com/verne/2015/09/24/.../1443080571_244447.htm/

Por Jaime Rubio Hancock

\title{
TU CEREBRO Y TÚ
}

\section{No es verdad que solo usemos el $10 \%$ de nuestro cerebro}

The Guardian dice que este bulo es "el mayor mito sobre el cerebro de la historia": un 48\% de los profesores británicos aún lo cree. Según Snopes, ni siquiera está claro su origen. Lo cierto es que usamos todas las áreas de nuestro cerebro, incluso cuando estamos descansando. Es verdad que el cerebro es muy plástico (podemos vivir con medio) y que no usamos todo a la vez, ya que algunas zonas están especializadas: cuando caminamos, por ejemplo, las partes centradas en la actividad motora son más activas que otras. Pero no hay una parte del cerebro que no haga nada y que esté esperando a que la activemos para tener superpoderes.

\section{La realidad tal y como la percibimos se genera en nuestro cerebro}

Damos significado a voces y sonidos a partir de ondas de presión del aire. Lo mismo ocurre con c olores y objetos: en realidad nuestro cerebro solo recibe señales de fotones reflejados. Por este motivo, no es extraño que las ilusiones ópticas puedan engañarnos.

\section{Vemos el mundo en fragmentos estrechos y desarticulados}

Solo vemos una porción muy pequeña del espacio. Tenemos que mover los ojos para leer porque la mayor parte de la página en realidad la vemos borrosa. No nos damos cuenta de esto porque en el momento en el que sentimos curiosidad por alguna parte del mundo, nuestros ojos se mueven para completar los detalles que faltan. Mientras nuestros ojos están en 
movimiento, deberíamos ver una mancha borrosa, pero nuestros cerebros editan y completan esta imagen.

\section{La imagen que tenemos de nuestro cuerpo es dinámica y flexible}

Podemos engañar a nuestro cerebro para hacerle creer que un brazo de goma o una mano de realidad virtual forma parte de nuestro cuerpo. Hay gente que sufre un síndrome (desorden de identidad de la integridad corporal) que le hace creer que una de sus extremidades no le pertenece: un hombre estaba convencido de que los médicos le habían cosido un miembro de un cadáver para gastarle una broma.

\section{Nuestro comportamiento es en gran medida automático, aunque nos parezca que lo controlamos}

El hecho de que podamos conducir un coche a 100 kilómetros por hora en la autopista mientras pensamos en otras cosas es una muestra de lo que puede a sumir el cerebro por su cuenta. La adicción es posible porque mucho de lo que hacemos es automático, incluyendo objetivos y deseos.

Mucha gente puede coger y comenzar a usar un peine que se les ha ofrecido sin tener idea de por qué. Cuando somos impulsivos, actuamos aunque sepamos que no debemos.

\section{Las neuronas son muy lentas.}

Nos parece que pensamos más rápido que los ordenadores, pero las neuronas solo envían señales unas pocas veces por segundo y las ondas beta del cerebro tienen entre 14 y 30 ciclos por segundo. En comparación, las computadoras hacen mil millones de operaciones por segundo. 